\title{
PROCESSOS DE PRIVATIZAÇÃO DA EDUCAÇÃO BÁSICA NO BRASIL E NA AMÉRICA LATINA Apresentação
}

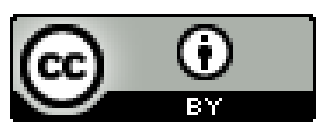

Educação: teoria e prática, Rio Claro, SP, Brasil - eISSN: 1981-8106

Está licenciada sob Licença Creative Common

Os processos de privatização da educação vêm se acentuando nas últimas décadas no Brasil e América Latina. Diversas estratégias privatizantes vêm sendo efetivadas, configurando um novo cenário que, em última instância, coloca em cheque conquistas recentes referentes ao direito à educação.

Este número temático apresenta e divulga pesquisas, debates e discussões acerca da privatização da educação básica, realizadas no âmbito do IV Seminário Internacional de Pesquisa do Grupo de Estudos e Pesquisa em Política Educacional - GREPPE, ocorrido na Faculdade de Educação da Unicamp em Campinas/SP, em 2014. A proposta do número temático emerge da necessidade de sistematização, divulgação e apresentação à comunidade, em formato de artigos em periódico especializado, dos debates acerca da temática. Aos trabalhos apresentados no evento se somam outros que paralelamente se articulam e ensejam maior aprofundamento e compreensão diante da temática geral abordada - a privatização da educação básica no Brasil e América Latina.

Os artigos aqui apresentados procuram explorar e abordar criticamente os limites e as possibilidades da temática, oferecendo aos profissionais ligados à área subsídios para que possam (re) pensar, (re) construir de forma autônoma sua compreensão sobre os processos de privatização da educação básica que vem ocorrendo em nosso país e na América Latina, porém com um compromisso fundamental - o direito de todos à uma educação pública de qualidade.

Optamos por organizar o número temático em dois momentos centrais: o primeiro com artigos que abordam os processos de privatização no cenário internacional e, o segundo, com artigos acerca dos processos de privatização no Brasil. Os artigos referentes ao Brasil foram organizados considerando-se primeiramente aqueles que discutem os processos de privatização na gestão educacional, depois os que abordam tais processos nos diferentes níveis e modalidades de ensino e, por fim, um artigo que reafirma a importância dessa temática - os processos de privatização e a violação do direto à educação. É importante esclarecer que essa construção tem simplesmente a função de facilitar a apresentação dos trabalhos para os leitores, no entanto, os artigos e trabalhos desenvolvidos nesse numero temático se articulam, complementam e suscitam novas ideias e relações.

A seguir apresentamos brevemente os artigos segundo a organização explicitada e a ordem em que se apresentam neste número temático. 
Os dois primeiros artigos abordam processos de privatização da educação no âmbito internacional. Iniciamos com o artigo "A privatização da educação no cenário internacional: reflexões sobre a agenda Pós-2015", de autoria de Giovanna Modé Magalhães (Doutoranda na Universidade de São Paulo - USP e Coordenadora de comunicação e mobilização da Campanha Latino-Americana pelo Direito à Educação - CLADE). A autora, à luz do Direito Internacional dos Direitos Humanos, discute algumas das expressões de tal fenômeno no campo internacional e seus consequentes riscos para a consolidação de sistemas públicos de educação. A análise é realizada a partir de algumas reflexões decorrentes da construção da nova agenda de educação e de desenvolvimento Pós 2015, processo ainda em curso que vem ocorrendo no âmbito das Nações Unidas e que estabelecerá novos compromissos e metas a serem cumpridas pelos Estados membros até o ano de 2030. Através da análise de documentos preparatórios que embasarão estes novos acordos, a autora indica disputas relevantes na conceitualização do propósito da educação.

O segundo artigo: "Privatización de la educación y poder corporativo: El fenómeno en una comuna urbano-popular en Santiago de Chile”, de autoria de Diego Parra Moreno e Juan González López (Universidad de Chile) expõe resultados de um estudo de caso acerca da privatização da educação obrigatória no Chile, na comuna urbano-popular de la Pintana, entre os anos de 1995 e 2014. Os resultados indicam o crescimento e consolidação dos mantenedores privados e das alianças entre o público e o privado, além de vínculos com empresas nacionais e transnacionais. O estudo aponta, ainda, para a crescente influencia dos mantenedores privados e suas redes no sistema educativo por meio de diversos processos de privatização.

Os demais artigos se referem aos processos de privatização no Brasil. Os dois primeiros abordam questões relativas à privatização da gestão educacional. $\mathrm{O}$ artigo "Mudanças organizacionais na gestão da escola e sua relação com o mundo empresarial: aprofundamento da privatização na educação básica brasileira?", de Theresa Maria Freitas Adrião (Universidade Estadual de Campinas - UNICAMP) e Teise de Oliveira Guaranha Garcia (Universidade de São Paulo - USP/Ribeirão Preto), aborda transformações na gestão empresarial capitalista nas últimas décadas e sua incidência sobre proposições para a gestão da escola pública. Conclui-se que as soluções apresentadas como esforço de generalização da lógica capitalista de gestão no interior da escola não contribuem para a qualidade da educação pública e para a democratização da gestão escolar, por não considerarem a especificidade do processo de trabalho pedagógico.

O artigo intitulado "Repolitização da Gestão Educacional no Brasil: Estratégia de Gestão no Âmbito Público, das autoras Katya Lacerda Fernandes e Rosilene Lagares (Universidade Federal do Tocantins - UFT), problematiza a respeito da ressignificação da gestão, mediante a introjeção de um aparato conceitual e procedimental que reifica a lógica privada no interior da gestão pública. A partir da perspectiva do método materialista histórico-dialético, evidenciam-se os resultados parciais de uma pesquisa bibliográfica e documental, acerca dos desdobramentos da reforma estatal iniciada no final do século XX na orientação do processo de gestão municipal da educação na contemporaneidade. Conclui-se que a confluência entre gestão e gerencialismo expressa um processo de repolitização vinculado à proposta liberal-corporativa de redefinição do Estado, que estabelece em suas bases a reiteração do 
imbricamento entre as noções de público e privado, o que implica a alteração do sentido do que seja gestão, direito e cidadania.

Também no âmbito dos processos de privatização da educação no Brasil, há artigos que tratam de programas e /ou processo de privatização nos diferentes níveis e modalidades da educação básica.

Acerca da privatização da educação infantil este número temático traz dois artigos. $\mathrm{O}$ primeiro deles intitula-se - "O atendimento privado subsidiado na educação infantil: os convênios e contratos administrativos em análise", de Caroline de Fátima Nascimento de Jesus Azevedo (Mestre pela Universidade Estadual Paulista - UNESP/Rio Claro) e Raquel Fontes Borghi (Universidade Estadual Paulista - UNESP/Rio Claro). As autoras analisam os instrumentos jurídicos adotados em cinco municípios do interior paulista (Araras, Hortolândia, Limeira, Piracicaba e Sumaré) em parcerias com instituições privadas lucrativas para a oferta de vagas na educação infantil. Trata-se de uma pesquisa qualitativa, de natureza documental. Por meio da análise de conteúdo constatou-se que os programas municipais não correspondem a uma política transitória para a oferta de vagas na educação infantil, pois fixam prazos longos de vigência das parcerias e preveem a possibilidade de prorrogá-las. Também se observou que a transferência de responsabilidades quanto à execução do atendimento às entidades privadas de finalidade lucrativa, a utilização de termos vagos ou imprecisos e a falta de mecanismos de fiscalização do atendimento pelas prefeituras constituem uma estratégia política de privatização da educação infantil.

O segundo artigo acerca da privatização da educação infantil é intitulado "Algumas reflexões sobre uso dos Indicadores da Qualidade na Educação Infantil em um estudo de caso”, de Jaqueline dos Santos Oliveira (Doutoranda na Universidade Estadual Paulista UNESP/Rio Claro). O artigo apresenta alguns resultados de pesquisa de mestrado cujo objetivo foi caracterizar e analisar o Programa Bolsa Creche e as condições de oferta em instituições de educação infantil municipal e privada concessionária. Os resultados permitem constatar que, os Indicadores da Qualidade na Educação Infantil constituem-se um importante instrumento de avaliação e planejamento, no entanto, observa-se como desafios: o uso do instrumento, a mobilização da comunidade escolar, o tempo separado para avaliação, e o compromisso e esforço coletivo na melhoria da qualidade das instituições de educação infantil.

Relacionados ao ensino fundamental, apresenta-se o artigo: "A qualidade do ensino público e a privatização via Programa Mais Educação”, de Elisangela Maria Pereira Schimonek (Doutoranda na Universidade Estadual de Campinas - Unicamp/SP). A autora analisa as implicações do Programa Mais Educação (2010-2013) na garantia de uma educação de qualidade a partir do estabelecimento de parcerias público-privadas e voluntariado. O referido programa integra o Plano de Desenvolvimento da Educação e objetiva a ampliação da jornada escolar por meio da oferta de atividades complementares no contraturno escolar. A intenção proclamada é reduzir as desigualdades educacionais, promover a valorização da diversidade cultural e garantir uma educação de qualidade. Para tanto, procura-se induzir a participação de atores da sociedade civil no mapeamento de espaços para o funcionamento da educação em tempo integral, na gestão e na oferta de atividades complementares. Trata-se de um estudo qualitativo, que evidencia uma política focalizada e pautada no discurso da participação da sociedade civil como 
mecanismo de assunção de responsabilidades do Estado cujos impactos para a qualidade da educação precisam ser analisados.

Outro artigo que trata da privatização no ensino fundamental intitula-se: "A Opacidade nas Relações Estabelecidas entre o Setor Privado e a Educação Pública Estadual de Mato Grosso", de Maria Clara Ede Amaral (Centro de Formação e Atualização dos Profissionais da Educação Básica Secretaria do Estado de Educação de Mato Grosso - CEFAPRO/SEDUC/MT) e Regiane Helena Bertagna (Universidade Estadual Paulista - UNESP/Rio Claro). As autoras analisam a relação entre duas organizações privadas - a Fundação CESGRANRIO (CES) e o Instituto Ayrton Senna (IAS) - com o governo estadual de Mato Grosso, por meio da análise da fala dos participantes da pesquisa e suas percepções quanto às informações sobre as parcerias, no período de 2006-2008. Foram sujeitos da pesquisa profissionais que atuaram nesta rede de ensino nos municípios de Cuiabá e Cáceres, a saber: gestores, coordenadores pedagógicos e professores, profissionais da Secretaria de Estado de Educação de Mato Grosso - SEDUC/MT. Observa-se a crescente adesão a modelos privados na educação pública, por meio de organizações que introduzem o modelo de administração empresarial, que por sua vez, influencia o funcionamento das redes públicas a partir da lógica de mercado, e muitas vezes, alicerçadas em transações comerciais opacas e não-transparentes, ferindo o princípio federal da Transparência Pública e as relações sociais e escolares.

Outro conjunto de artigos trata de programas e processos que envolvem a privatização no ensino médio. São dois artigos que abordam o projeto Jovem do Futuro do Unibanco em contextos diferentes, um na região Sul e o outro na região Centro-oeste do Brasil. O primeiro deles intitulado: "Relações entre o público e o privado na educação: o Projeto Jovem de Futuro do Instituto Unibanco", de autoria de Vera Maria Vidal Peroni (Universidade Federal do Rio Grande do Sul -UFRGS) e Maria Raquel Caetano (IFSUL/Campus Charqueadas) faz parte da pesquisa "Parcerias entre sistemas públicos e instituições do terceiro setor: Brasil, Argentina, Portugal e Inglaterra implicações para a democratização da educação". A pesquisa vem sendo realizada pelo Grupo de Pesquisa "Relações entre o Público e o Privado na Educação" do Programa de Pós-Graduação em Educação da Universidade Federal do Rio Grande do Sul. Neste texto, as autoras dão prioridade para dois aspectos - sujeitos e conteúdo da proposta - na análise do Projeto Jovem de Futuro do Instituto Unibanco.

O outro artigo acerca dos processos de privatização no ensino médio é intitulado "Projeto Jovem de Futuro: uma Tecnologia do Instituto Unibanco para a Gestão de Escolas Púbicas de Ensino Médio", de Regina Tereza Cestari de Oliveira e Maria Aparecida Canale Balduino (Universidade Católica Dom Bosco - UCDB/Mato Grosso). O artigo focaliza o Projeto Jovem de Futuro, apresentado pelo Instituto Unibanco, pré-qualificado no Guia de Tecnologias Educacionais do Ministério da Educação (MEC), efetivado por meio de parceria realizada com o MEC, governos dos estados (Ceará, Goiás, Mato Grosso do Sul, Pará e Piauí) e o Instituto, no âmbito do Programa Ensino Médio Inovador/Jovem de Futuro, para a gestão de escolas de Ensino Médio. Mostra que se trata de proposta de gestão escolar para resultados, com base na lógica de mercado e busca problematizar, mediante análise documental, as orientações do Programa, que influenciam as políticas educacionais brasileiras para o Ensino Médio. 
Sobre o ensino profissionalizante temos o artigo: "A Política de Educação Profissional e a Mercantilização da Educação: o Público e o Privado na Execução do Pronatec”, de Maria Luzirene Oliveira do Nascimento (Mestranda na Universidade Federal do Piauí -UFPI). O trabalho é dedicado à análise da implantação do Programa Nacional de Acesso ao Ensino Técnico e Emprego (Pronatec), criado no Governo Dilma (2011-2014), que integra as ações da política de Educação Profissional. A autora aborda a relação entre o público e o privado que permeia essa proposta, vez que, o referido programa tem sido executado pela União em parceria com os Estados, Municípios e setores da iniciativa privada. No âmbito do debate sobre privatização da educação a autora destaca a Bolsa-Formação e o Fies Técnico empresa, que possibilita a execução do ensino técnico por empresas e o Sistema S com o repasse de recursos públicos para a oferta de cursos técnico.

Finalizando o número temático e reafirmando a importância da discussão da temática na luta pelo direito à educação o artigo intitulado: "Direito à educação e sistemas privados de ensino nas redes públicas: hipóteses para análise jurídica”, de Salomão Barros Ximenes (Universidade Federal do ABC $\mathrm{UFABC}$ ) retoma o marco conceitual sobre o direito humano à educação desenvolvido pelo Comitê DESC da ONU. Com base neste marco conceitual o autor propõe que seja analisado o impacto dos processos de privatização da educação no Brasil, mais especificamente aqueles representados pela crescente adoção de sistemas privados de ensino nas redes públicas. Nessa sistematização, de um lado evidencia que a privatização pode exacerbar e qualificar violações, principalmente quanto aos deveres de não discriminação, adaptação, gestão democrática e autonomia relativa de professores e escolas. Como resultado, oferece uma análise inicial para as questões jurídicas que poderão ser mensuradas nas pesquisas sobre o assunto.

Na seção documentos apresentamos a "Carta Aberta de Campinas" produzida no âmbito do IV Seminário Internacional de Pesquisa do Grupo de Estudos e Pesquisa em Política Educacional GREPPE que trata do posicionamento dos participantes frente à discussão promovida e fomentada durante o evento suscitadas pelas pesquisas, trabalhos e debates realizados e, que culminaram na elaboração de uma carta do evento aberta à comunidade, a aqueles e aquelas os quais compartilharam as mesmas ideias discutidas em defesa do direito humano à educação pública de qualidade.

Finalmente, como organizadoras desse número temático, agradecemos primeiramente a Revista Educação: Teoria e Prática pela oportunidade de socializarmos pesquisas, reflexões e debates suscitados no IV Seminário Internacional de Pesquisa do Grupo de Estudos e Pesquisa em Política Educacional GREPPE, a respeito da temática da privatização na educação. Agradecemos, também, a colaboração dos pesquisadores, professores, profissionais ligados à área educacional que participaram do número temático, bem como a todos os participantes do já referido evento do GREPPE, que possibilitaram que as ideias lá apresentadas e iniciadas fossem aqui sistematizadas e expandidas de maneira a contribuir para a construção de novas perspectivas de estudo e luta pelo direito à educação pública de qualidade.

Profa. Dra. Regiane Helena Bertagna Profa. Dra. Raquel Fontes Borghi 